\title{
Psychiatric comorbidity among children and adolescents with dyslexia
}

\author{
Alaa M. Darweesh ${ }^{*}$ (D, Yasser M. Elserogy, Hossam Khalifa, Romany H. Gabra and Mohamed A. El-Ghafour
}

\begin{abstract}
Background: One of the most consistent findings in childhood psychopathology literature is that children with dyslexia frequently presented with additional psychiatric disorders. Over $60 \%$ of children with dyslexia meets criteria for at least one additional diagnosis.

Aim of results: Dyslexia shows high comorbidity with $\mathrm{ADHD}, \mathrm{ODD}$, and $\mathrm{CD}(18 \%, 14 \%$, and $8 \%$, respectively) than ccontrols that affect dyslexic boys more than girls. Dyslexic group show marked increase in internalizing and externalizing syndromes than control group. Dyslexic girls show more internalizing behaviors than dyslexic boys, unlike externalizing syndromes which was more evident in boys).
\end{abstract}

Conclusion: High comorbidity of other psychiatric disorders with dyslexia gets attention to evaluate students with dyslexia for other psychiatric comorbidity and referring them for psychiatric management.

Keywords: Dyslexia, Psychiatric comorbidity, ADHD, ODD, CD

\section{Background}

Learning is a process by which individuals acquiring new, or modifying existing, knowledge, behaviors, skills, values, or preferences and may involve synthesizing different types of information [1]. Dyslexia is defined as reading achievement below the expected level for a child's age, education, and intelligence, with the impairment interfering significantly with academic success or the daily activities that involve reading. According to DSM-IV-TR, if a neurological condition or sensory disturbance is present, the reading disability exhibited exceeds that usually associated with the other condition [2]. The British Dyslexia Association definition describes dyslexia as a learning difficulty that primarily affects the skills involved in accurate and fluent word reading and spelling" and is characterized by "difficulties in phonological awareness, verbal memory and verbal processing speed [3].

The prevalence of dyslexia shows considerable crossnational variation. An estimated $4 \%$ of school-age children in the USA have dyslexia [4]. In Australia, approximately $10 \%$ of the students suffer from dyslexia [5].

\footnotetext{
* Correspondence: Assiutbird25@Yahoo.com

Department of Neurology and Psychiatry, Assiut University, Assiut, Egypt
}

In Egypt, it was found that, the prevalence of reading difficulties among the population surveyed in Assiut City (among 2878 children from the 2nd and 3rd grades in elementary schools ) was $1 \%$ and boys to girls ratio was 2.7 to 1 [6]. The prevalence was far lower than that reported in western countries. Another study was carried out at Abbassia District in Cairo, Egypt, and found dyslexia among primary school children was $2.6 \%$ [7]. How the Arabic language is written and read probably, contributes to the low prevalence of reading difficulties among Arabic speaking populations [6].

One of the most consistent findings in the childhood psychopathology literature is that children with dyslexia frequently presented with additional psychiatric disorders, over $60 \%$ of children with dyslexia meets criteria for at least one additional diagnosis [8].

Understanding comorbidity is important because the presence of an additional disorder may affect the expression and severity of the clinical picture, requiring specific treatments and interventions. Patients with comorbidity compared to those without comorbidity usually exhibit more severe neurocognitive impairment, negative academic experience, social outcomes, and lower treatment
Springer Open

(c) The Author(s). 2020 Open Access This article is licensed under a Creative Commons Attribution 4.0 International License, which permits use, sharing, adaptation, distribution and reproduction in any medium or format, as long as you give appropriate credit to the original author(s) and the source, provide a link to the Creative Commons licence, and indicate if changes were made. The images or other third party material in this article are included in the article's Creative Commons licence, unless indicated otherwise in a credit line to the material. If material is not included in the article's Creative Commons licence and your intended use is not permitted by statutory regulation or exceeds the permitted use, you will need to obtain permission directly from the copyright holder. To view a copy of this licence, visit http://creativecommons.org/licenses/by/4.0/. 
response. Also, children with comorbid problems have more secondary problems, such as low self-esteem, behavioral problems, and dropping out of school [9].

The aim of this study is psychiatric evaluation of a group of children and adolescents with dyslexia.

\section{Methods}

The dyslexic participants of this study are students previously diagnosed as dyslexia according to DSM IV-TR, which include screening of 1080 students from 7 to 15 years. They were all student detected to have dyslexia through screening of primary school children in Assiut City [10]. Diagnosis of dyslexia in the previous study and the present study is based on clinical presentation and confirmed through Dyslexia Diagnostic Scale. The original dyslexia diagnostic scale was developed by Sherman, 1985. Translation of the original dyslexia diagnostic scale into Arabic language to suit the Egyptian culture was carried out by Professor Nasra Abdel megied Galgel, Kafer Elshikh, Tanta University, Faculty of Education, (2006). This scale was used to confirm the diagnosis of dyslexia. The studied population included 50 students ( 27 males and 23 females) with dyslexia and a control group of 50 students (26 males and 24 females) without dyslexia. They were pair-wise matched on age, gender, and cognitive level.

\section{Study tools}

\section{Stanford Binet Test}

One of the first intelligence tests is the Binet-Simon test with its versions quickly gained support in the psychological community, many of which further spread to the public.

The Stanford-Binet Intelligence Test: Fourth Edition (SB: FE) is a standardized test that measures intelligence and cognitive abilities in children and adults, from age 2 through mature adulthood [11].

\section{Socio economic status}

This scale is an Arabic version designed by Abd-ElTawab, in 2004 [12], to measure the socioeconomic level of families.

It includes four domains:

1. Parents' educational level including eight items.

2. Parents' occupation including two items.

3. Total family monthly income including six items.

4. The lifestyle level including three items.

The sums of scores give the total score of the variable, then calculation of mean and standard deviation of scores of the total sample. Classification of individual was performed according to the following: score higher than (mean $+1 \mathrm{SD})$ is considered high socioeconomic level, score lower than (mean - 1SD) is considered low, and score in between is considered middle.
Arabic version of Child Behavioral Checklist of Achenbach (Achenbach T. M., 1991) [13]

In the present study, behavioral symptoms were assessed by application of Child Behavioral Checklist (CBCL) parent form, which is a widely used method for identifying problem behavior in children. Problems are identified by a respondent who knows the child well, usually a parent or other care giver.

In the revised version (2001) of the CBCL/6-18 it is made up of eight syndrome scales: withdrawn behavior, somatic complaints, anxious depressed, social problems, thought problem, attention problems, delinquent behavior, and aggressive behavior. These groups are classified into two higher orders: internalizing and externalizing syndromes. The CBCL also scored for Competence Scale (optional) for activities, social relations, school, and total competence score [14].

Competence Scale, which is divided into activities, school, and social subscales

Problem Scale, which is also divided into

- Internalizing manifestation calculated by summation of first three sub scales (withdrawn, anxious, and social problems)

- Externalizing manifestation calculated by summation of last two sub scales (delinquent and aggressive behaviors)

\section{Arabic version of Mini Kid rating scale: (David Sheehan 1998 [15] "translated by Ghanem M. 1999")}

The Mini International Neuropsychiatric Interview-Kid (MINI-Kid) is a structured interview for psychiatric evaluation and outcome-tracking in clinical psychopharmacology trials and epidemiological studies. It takes approximately $15 \mathrm{~min}$ to complete. Its sensitivity was substantial and specificity was excellent.

The MINI-kid is divided into modules identified by letters, each corresponding to a diagnostic category.

- At the beginning of each diagnostic module (except for psychotic disorders module), screening question(s) corresponding to the main criteria of the disorder are presented in a gray box.

- At the end of each module, diagnostic box (es) permits the clinician to indicate whether diagnostic criteria are met.

Participants were subjected to confirmatory tests for diagnosis of dyslexia (wide range achievement test). After the confirmation of the diagnosis, IQ was examined by a trained psychologist through Stanford Binet Test for both patient and controls. Evaluation of socioeconomic status was carried out, after explanation of the steps and aims of the research for parents and 
participants, and a written informed consent was taken from the parents. Both patients and control were examined through MINI kid scale for different psychiatric disorders in an individual base in the outpatient psychiatric clinic of Assiut University Hospital. Parent form of CBCL was given to the parents (caregiver in case of absence of parents) to answer the questionnaire or if they cannot read the examiner ask them the question and put the marks according to the response of the parent.

\section{Statistical methods}

The studied variables were coded for computerized data entry. For easy manipulation and accurate statistical analysis, software package SPSS Ver. 16 (SPSS Inc. Chicago, IL, USA) and excel for figures were used.

Descriptive statistics, e.g., frequency, percentage, mean, standard deviation, standard errors were calculated. $p$ value considered significant when it is < 0.05 .

For inferential analysis of effect of gender on different variables of CBCL items factorial ANCOVA and Student's $t$ test, chi-square test was used.

\section{Ethical consideration}

The protocol and study design of this thesis was approved by ethical committee of faculty of medicine, Assiut University. An informed written consent was obtained and signed from parents or caregivers of the participants to participate in the study. Confidentiality was maintained during the whole study. The subjects in the study were not exposed to any risk and the provided health service was not affected by their participation in the study. The steps and results of the investigations in the work were explained to them. If any clinical problem with the participant was found they were informed and referred to be managed accordingly.

\section{Results}

\section{Demographic characteristics}

The mean age of dyslexic group was $9.68 \pm 1.77$ years, and $68 \%$ of them fall in the middle socioeconomic status (SES); males represent $54 \%$ of them. They have mean IQ of $94.44 \pm 4.19$. The control group is cross-matched as regards age SES and IQ with no significant difference among both groups (Table 1).

Evaluation of the studied groups through MINI-kid scale, there are significantly higher percentages of dyslexic group have ADHD (18\%), CD (8\%), and ODD (14 $\%)$ than the control group (4\%, $0.0 \%$, and $2 \%$, respectively) ( $p$ value $0.02,0.04,0.02$ respectively).

There were two cases of panic disorder (4.0\%), one case of agoraphobia (2.0\%), one case of separation anxiety disorder $(2.0 \%)$, and three cases of specific phobias (3.0\%) in dyslexic group in contrast to no case in control group, however, of insignificant difference.
Table 1 Demographic characteristics of dyslexic students and controls

\begin{tabular}{|c|c|c|c|c|c|c|}
\hline \multirow[t]{3}{*}{ Demographics } & \multirow{2}{*}{\multicolumn{2}{|c|}{$\frac{\text { Dyslexic group }}{(\text { No. }=50)}$}} & \multirow{2}{*}{\multicolumn{2}{|c|}{$\frac{\text { Control group }}{(\mathrm{No} .=50)}$}} & \multirow{3}{*}{$\begin{array}{l}\mathrm{t} \\
\text { test }\end{array}$} & \multirow{3}{*}{$\begin{array}{l}P . \\
\text { value }\end{array}$} \\
\hline & & & & & & \\
\hline & No. & $\%$ & No. & $\%$ & & \\
\hline Boys & 27 & 54.0 & 26 & 52.0 & 0.76 & 0.841 \\
\hline Girls & 23 & 46.0 & 24 & 48.0 & & \\
\hline Age & \multicolumn{2}{|c|}{$9.68 \pm 1.77$} & \multicolumn{2}{|c|}{$10.5 \pm 2.09$} & 1.7 & 0.066 \\
\hline IQ & \multicolumn{2}{|c|}{$94.44 \pm 4.19$} & \multicolumn{2}{|c|}{$94.12 \pm 3.44$} & 1.88 & 0.677 \\
\hline \multicolumn{7}{|c|}{ Socioeconomic level } \\
\hline High & 12 & 24 & 8 & 16 & 0.74 & 0.597 \\
\hline Middle & 34 & 68 & 35 & 70 & & \\
\hline Low & 4 & 8 & 7 & 14 & & \\
\hline
\end{tabular}

There were no cases of depression, suicide, manic episode, dysthymia, social phobia, OCD, post-traumatic stress disorder, alcohol or drug dependence, tics, psychosis, appetite loss, polyphagia, nor adjustment disorder were detected in both dyslexic and control groups (Table 2, Fig 1).

When comparing boys and girls of dyslexic group, we found significant higher percentages of boys have ADHD $(22.2 \%)$ than girls $(13 \%),(p$ 0.04). Also, boys have significant higher percentage of $\mathrm{CD}(14.8 \%)$ in contrast of no case of $C D$ in girls $(p 0.02)$. In spite of higher percentage of dyslexic boys have ODD than girls the difference is insignificant (Table 3, Fig. 2).

The first part of CBCL is the Competence Scale which includes three sub-items: activities, social, and school

Table 2 Frequency distribution of different psychiatric disorders among dyslexic and control groups according to Mini Kid Scale

\begin{tabular}{|c|c|c|c|c|c|c|}
\hline \multirow[t]{2}{*}{ MINI kids variables } & \multicolumn{2}{|c|}{ Dyslexic $(\mathrm{No} .=50)$} & \multicolumn{2}{|c|}{ Control $(\mathrm{No} .=50)$} & \multirow[t]{2}{*}{$x^{2}$} & \multirow{2}{*}{$\begin{array}{l}\mathrm{P} \text {. } \\
\text { value }\end{array}$} \\
\hline & No. & $\%$ & No. & $\%$ & & \\
\hline Panic disorder & & & & & 6.25 & 0.153 \\
\hline Affected & 2 & 4.0 & 0 & 0.0 & & \\
\hline Agoraphobia & & & & & 4.11 & 0.315 \\
\hline Affected & 1 & 2.0 & 0 & 0.0 & & \\
\hline Separation Anxiety & & & & & 4.11 & 0.315 \\
\hline Affected & 1 & 2.0 & 0 & 0.0 & & \\
\hline Specific phobia & & & & & 6.25 & 0.079 \\
\hline Affected & 3 & 6.0 & 0 & 0.0 & & \\
\hline ADHD & & & & & 9.35 & $0.025^{*}$ \\
\hline Affected & 9 & 18.0 & 2 & 4.0 & & \\
\hline Conduct Disorder & & & & & 7.81 & $0.041^{*}$ \\
\hline Affected & 4 & 8.0 & 0 & 0.0 & & \\
\hline ODD & & & & & 9.35 & $0.027^{*}$ \\
\hline Affected & 7 & 14.0 & 1 & 2.0 & & \\
\hline GAD & & & & & 0.115 & 1.000 \\
\hline Affected & 1 & 2.0 & 1 & 2.0 & & \\
\hline
\end{tabular}




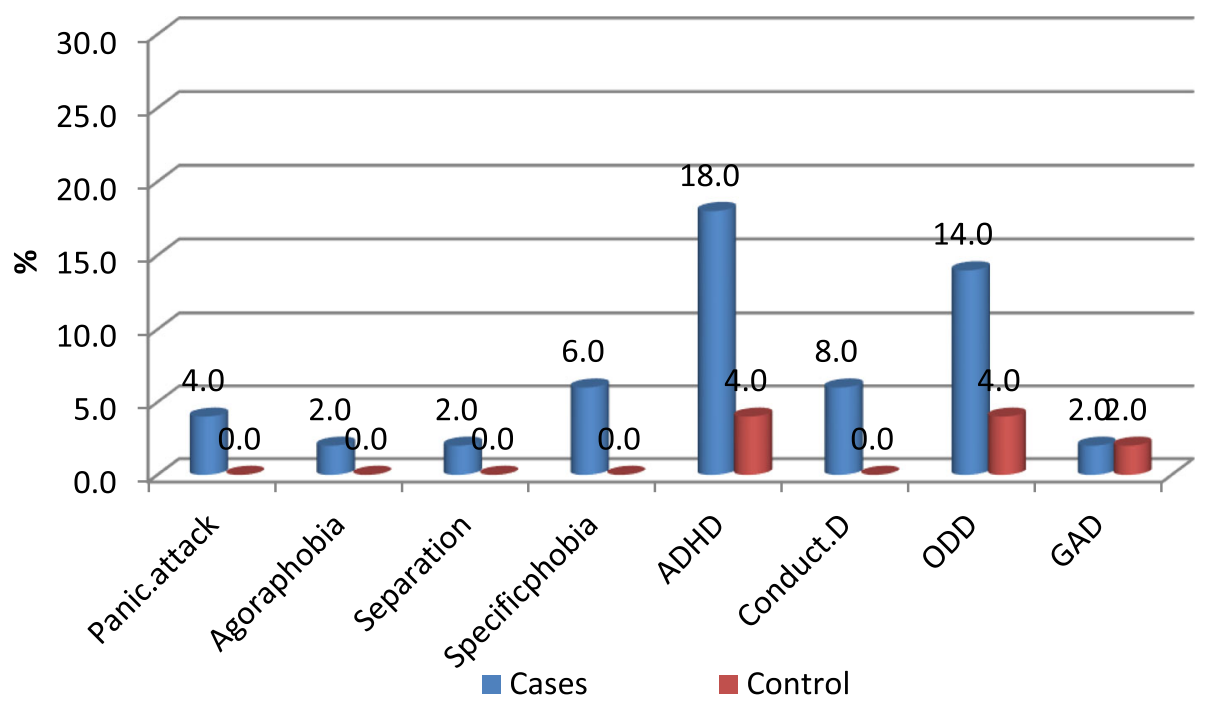

Fig. 1 Frequency distribution of different psychiatric disorders among dyslexic and control groups according to MINI Kid Scale

items in addition to the total competence score. It was found that significant higher percentages of dyslexic group have abnormal levels of total competence (30\%), activities $(44 \%)$, and school (12\%) than the controls $(8 \%$, $14 \%$, and 0.0 , respectively) ( $p$ values $0.01,0.004$, and 0.03). However, the difference as regards social competence is of insignificance (Table 4, Fig. 3).

Study of the gender differences effect among dyslexic and control group, showed that significant differences in activities and school scoring, but the main effect of dyslexia is significantly higher in activities without significant gender main effect, unlike school subscale which shows marked gender difference suggesting that females is affected more in school aspect and males more affected in activities scale (Table 5).

Dyslexics have significantly higher mean scores of withdrawn, anxious, attention, and delinquent subscales ( $p$ values $0.042,0.001,0.004$, and 0.026 , respectively). Also, they have significant higher score in internalizing, externalizing, and total problem mean score ( $p$ values: $0.003,0.007,0.000$, respectively) than controls (Table 6).
Study the interaction between dyslexia and gender on the internalizing and externalizing symptoms and disorders by comparing the mean scores of dyslexic and control group on the problem scale of CBCL. It revealed that significant effect of dyslexia on mean scores of anxiety, attention problems, aggression, and delinquent scales. Whereas, gender will affect the mean scores of dyslexic group, being girl significantly increases the mean scores of withdrawal and anxiety while being a boy increases that of delinquent behavior. Also, dyslexia significantly increases the mean scores of both internalizing and externalizing scales and total problem scale. Whereas, gender affect the mean scores of dyslexic group; being girl significantly increases the mean scores of internalizing scale and being boy increases the mean scores of externalizing scale, while there is no significant effect on the total score of problem scale of CBCL (Table 7).

\section{Discussion}

It has long been recognized that dyslexia often co-occurs with a range of other behavioral problems [16].

Table 3 Frequency distribution of ADHD, CD, and ODD in boys and girls of studied groups according to MINI kids scale

\begin{tabular}{|c|c|c|c|c|c|c|c|c|c|c|}
\hline \multirow{3}{*}{$\begin{array}{l}\text { MINI } \\
\text { Kids } \\
\text { variables }\end{array}$} & \multicolumn{4}{|c|}{ Boys } & \multicolumn{4}{|c|}{ Girls } & \multirow[t]{3}{*}{$x^{2}$} & \multirow{3}{*}{$\begin{array}{l}P \\
\text { value }\end{array}$} \\
\hline & \multicolumn{2}{|c|}{ Dyslexic (N=27) } & \multicolumn{2}{|c|}{ Control N=26) } & \multicolumn{2}{|c|}{ Dyslexic ( $N=23)$} & \multicolumn{2}{|c|}{ Control (N=24) } & & \\
\hline & No. & $\%$ & No. & $\%$ & No. & $\%$ & No. & $\%$ & & \\
\hline $\mathrm{ADHD}$ & & & & & & & & & 11.1 & $0.042^{*}$ \\
\hline Affected & 6 & 22.2 & 1 & 3.7 & 3 & 13.0 & 1 & 3.7 & & \\
\hline Conduct D & & & & & & & & & 12.8 & $0.023^{*}$ \\
\hline Affected & 4 & 14.8 & 0 & 0.0 & 0 & 0.0 & 0 & 0.0 & & \\
\hline ODD & & & & & & & & & 6.63 & 0.276 \\
\hline Affected & 4 & 14.8 & 1 & 3.7 & 3 & 11.1 & 1 & 3.7 & & \\
\hline
\end{tabular}

${ }^{*} p<0.05$ 


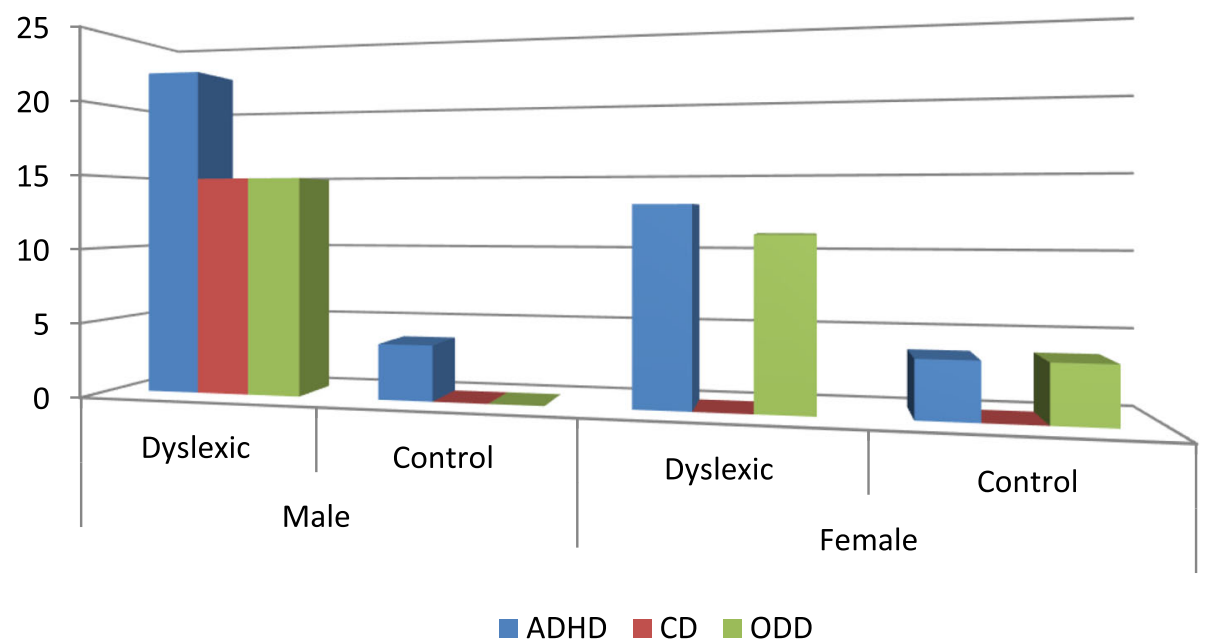

Fig. 2 Frequency distribution of $A D H D, C D$, and ODD in boys and girls of studied group according to MINI kids scale

The present study revealed that ADHD, CD, and ODD are increasingly associated with individuals with dyslexia.

Many researches tried to study the comorbidity of ADHD in dyslexia, the results were widely variable which ranged from $18 \%$ to approximately $60 \%$, with a median prevalence of $38.2 \%$ across studies. The prevalence of ADHD among students with dyslexia in previous studies is roughly seven times

Table 4 Frequency distribution of different levels of competence scale of CBCL among dyslexic and control group

\begin{tabular}{|c|c|c|c|c|c|c|}
\hline \multirow[t]{3}{*}{$\mathrm{CBCL}$ variables } & \multirow{2}{*}{\multicolumn{2}{|c|}{$\begin{array}{l}\text { Dyslexic group } \\
\text { No. }=50\end{array}$}} & \multirow{2}{*}{\multicolumn{2}{|c|}{$\begin{array}{l}\text { Control } \\
\text { No. }=50\end{array}$}} & \multirow[t]{3}{*}{$x^{2}$} & \multirow{3}{*}{$\begin{array}{l}P . \\
\text { value }\end{array}$} \\
\hline & & & & & & \\
\hline & No. & $\%$ & No. & $\%$ & & \\
\hline Activities & & & & & 13.38 & $0.004^{* *}$ \\
\hline Normal & 13 & 26.0 & 23 & 46.0 & & \\
\hline Borderline & 15 & 30.0 & 20 & 40.0 & & \\
\hline Abnormal & 22 & 44.0 & 7 & 14.0 & & \\
\hline Social & & & & & 7.78 & 0.107 \\
\hline Normal & 43 & 86.0 & 48 & 96.0 & & \\
\hline Borderline & 3 & 6.0 & 2 & 4.0 & & \\
\hline Abnormal & 4 & 8.0 & 0 & 0.0 & & \\
\hline School & & & & & 11.1 & $0.039^{*}$ \\
\hline Normal & 42 & 84.0 & 47 & 94.0 & & \\
\hline Borderline & 2 & 4.0 & 3 & 6.0 & & \\
\hline Abnormal & 6 & 12.0 & 0 & 0.0 & & \\
\hline Total Competence & & & & & 13.3 & $0.015^{*}$ \\
\hline Normal & 25 & 50.0 & 36 & 72.0 & & \\
\hline Borderline & 10 & 20.0 & 10 & 20.0 & & \\
\hline Abnormal & 15 & 30.0 & 4 & 8.0 & & \\
\hline
\end{tabular}

${ }^{*} p>0.05$

${ }^{* *} p>0.01$

***p $<0.001$

Normal subject ( $T$ score more than 33 )

Borderline ( $\mathrm{T}$ score between 30 and 33)

Abnormal subject (T score below 33 ) higher than the prevalence of ADHD in the general population, which is approximately 5\% [17]. These recorded figures are higher than that reported in the present study (18\%).

The wide variability of ADHD prevalence across studies is most likely due to different reasons. First, children with ADHD are assessed with different clinical instruments, and ways of recruitment using different diagnostic criteria (DSM or International Classification of Disease-Tenth Revision [ICD-10]). Moreover, the prevalence of dyslexia varies across different cultures depending on the complexity of the orthographic rules [18].

Between the two disorders, there is a bidirectional relationship since the comorbidity is very high if one examines children with dyslexia for ADHD or children with ADHD for dyslexia. That could be explained as ADHD and dyslexia shares a common, biological etiology that is based in a genetic predisposition to both disorders. Many studies have identified specific alleles that may be associated with increased risk for both ADHD and dyslexia [19], and a genetic link between symptoms of ADHD and academic achievement has also been supported by twin studies [20]. It is possible that deficits may be related to working memory and processing speed, as such difficulties are shared across ADHD and dyslexia [21].

In the present study, dyslexic group have high incidence of ODD (14\%) than the control, also, dyslexic boys have high prevalence (14.8\%) than girls (11.1\%). Willcutt and Pennington, (2000b) [22] were on agreement with this as they reported that although dyslexia is associated with elevations of possibility of ODD in both boys and girls, this effect is stronger for boys.

On the other hand, few studies tried to identify the relation between dyslexia and comorbid CD, all of it demonstrated that learning disabilities are accompanied by personality characteristics that predispose the individual to conduct disorder [23]. 


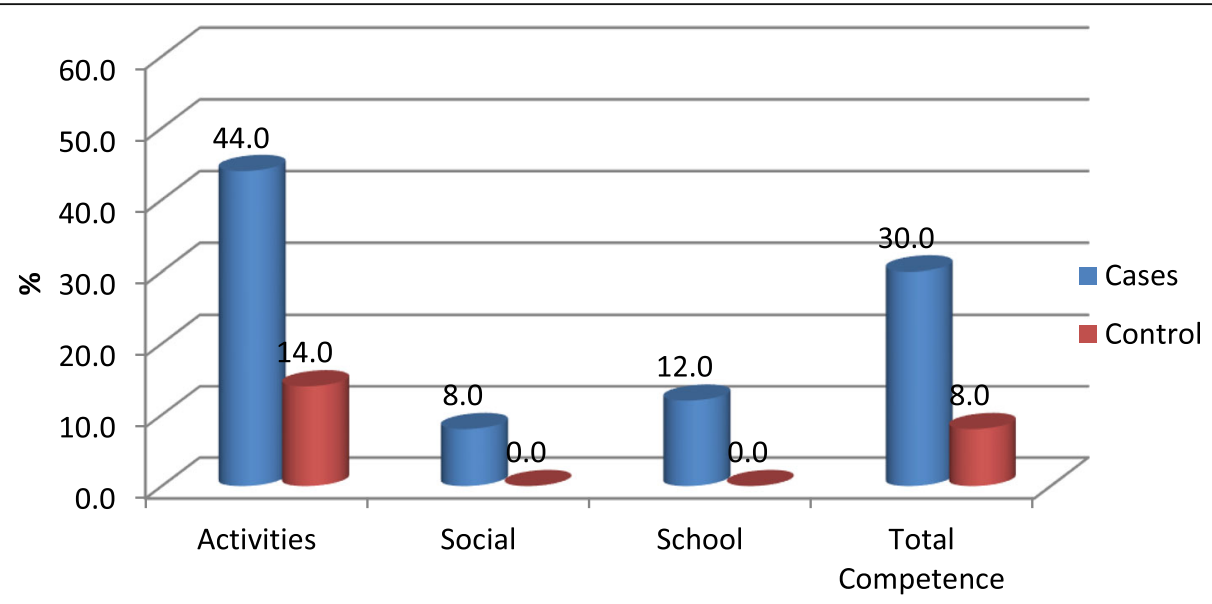

Fig. 3 Frequency distribution of different levels of competence scale of CBCL among dyslexic and control group

In addition, dyslexic youth have been described by parents as having more externalizing behaviors than peers in the community and have been reported to engage in violence twice as often as non-dyslexic youth. Persistence of such problems was reflected in higher rates of antisocial personality disorder diagnoses at age 19 among males with language impairments relative to males without RD [24].

Also, Goldston et al. (2007) [25] found that disruptive behavior disorders increased markedly in poor reader than in typical reader including conduct and oppositional disorders

It may be suggested that early reading delay causally influences later tendencies to antisocial behavior as a result of a series of processes that may include lower levels of attachment to the social order and feelings of frustration or lowered self-esteem [26].

Impact of dyslexia on social, school, and general activities In the present study, dyslexic individuals showed impairment in their general activities, abnormal social, and school competence.

In adolescence, dyslexic students who have a school performance comparable to the control group still show a weaker sense of school and social effectiveness, less hope, poor self-esteem, and motivation in committing to homework [27]. In support of this, Mai Eissa, (2010) [28] demonstrated that dyslexia affect self-esteem negatively. It was because feeling inferior to the others' with poor school achievement. Also, About $60 \%$ felt that their reading problems had influenced their peer relations negatively. They claimed that they had been teased or bullied because of their reading and writing difficulties.

As regards impaired school competence, it is more in girls than in boys, in the present study, it could be explained by the difference between boys and girls, in our society parents and teachers tend to value boys academic achievement more than girls so greater effort done for boys than girls. On the other hand, activities affected more in boys may be attributed to attention problems which are more common in boys that may have an impact on activities. Also increase in male disruptive manner making participation in sports and day time activities more difficult.

\section{The relation between dyslexia and internalizing symptoms}

Analysis of data show marked difference in internalizing manifestation between dyslexic and control individuals

Table 5 Gender effect on competence scale scores of CBCL among dyslexic and control groups

\begin{tabular}{|c|c|c|c|c|c|c|c|}
\hline \multirow[t]{3}{*}{$\mathrm{CBCL}$ variables } & \multicolumn{2}{|l|}{ Boys } & \multicolumn{2}{|l|}{ Girls } & \multicolumn{2}{|c|}{ Main effects } & \multirow{3}{*}{$\begin{array}{l}\text { Group x } \\
\text { Gender } \\
\text { interaction } \\
\text { F }\end{array}$} \\
\hline & Dyslexic & Control & Dyslexic & Control & Group & $\overline{\text { Gender }}$ & \\
\hline & Mean \pm SD & Mean \pm SD & Mean \pm SD & Mean \pm SD & $\mathrm{F}$ & $\mathrm{F}$ & \\
\hline Activities & $27.8 \pm 8.2$ & $32.2 \pm 4.8$ & $30.3 \pm 7.9$ & $34.6 \pm 5.8$ & $10.12^{* *}$ & 3.23 & 0.00 \\
\hline Social & $44.1 \pm 10.9$ & $46.1 \pm 6.7$ & $47.5 \pm 8.1$ & $44.4 \pm 7.5$ & 0.13 & 0.24 & 2.20 \\
\hline School & $47.4 \pm 6.5$ & $44.8 \pm 6.8$ & $39.3 \pm 8.3$ & $40.2 \pm 6.8$ & 0.40 & $20^{* *}$ & 1.54 \\
\hline Total Competence & $34.9 \pm 7.8$ & $36.6 \pm 4.2$ & $34 \pm 7.3$ & $36.1 \pm 6.6$ & 2.06 & 0.32 & 0.02 \\
\hline
\end{tabular}


Table 6 Mean Scores of dyslexics and controls on measures of Problem Scale of CBCL

\begin{tabular}{lllll}
\hline CBCL variables & $\begin{array}{l}\text { Dyslexic }(\mathrm{N}=50) \\
\text { Mean } \pm \mathrm{SD}\end{array}$ & $\begin{array}{l}\text { Control }(\mathrm{N}=50) \\
\text { Mean } \pm \mathrm{SD}\end{array}$ & $\begin{array}{l}\mathrm{t} \\
\text { test }\end{array}$ & $\begin{array}{l}\mathrm{P} . \\
\text { value }\end{array}$ \\
\hline Withdrawn & $56.52+8.21$ & $53.74+4.65$ & 4.30 & $0.042^{*}$ \\
Somatic & $51.92+3.86$ & $51.4+2.62$ & 1.06 & 0.432 \\
Anxious & $54.68+7.25$ & $51.1+2.37$ & 9.93 & $0.001^{* *}$ \\
Social Problems & $51.76+4.09$ & $50.94+2.95$ & 1.89 & 0.253 \\
Thought Problem & $50.88+2.8$ & $51.08+3.1$ & 0.82 & 0.736 \\
Attention & $55.12+9.21$ & $51.06+3.03$ & 9.90 & $0.004^{* *}$ \\
Delinquent & $55.28+8.44$ & $52.14+5.06$ & 4.30 & $0.026^{*}$ \\
Aggressive & $53.72+6.14$ & $52.06+2.42$ & 0.83 & 0.078 \\
Internalizing & $49.26+11.96$ & $42.9+8.26$ & 9.92 & $0.003^{* *}$ \\
Externalizing & $48.06+12.14$ & $42.16+8.86$ & 9.8 & $0.007^{* *}$ \\
Total Score & $49.5+9.99$ & $42.5+8.48$ & 9.66 & $0.000^{* *}$ \\
Other & $3.42+2.68$ & $2.32+2.02$ & 4.29 & $0.023^{*}$ \\
\hline
\end{tabular}

${ }^{*} p>0.05$

${ }^{* *} p<0.001$

mainly in depressed-anxious manifestation but there is some gender difference as these manifestations are more in girls than boys.

These results are consistent with the study of Capozzi et al. (2007) [29]. They found that 52\% recorded a pathological score on the internalizing scale, $26.4 \%$ recorded a pathological score on the externalizing scale, and the remaining $20.5 \%$ had a pathological score on both scales, while $31.5 \%$, obtained a pathological score on the Anxiety-Depression Scale. Lower percentages were recorded in the scales assessing somatic complaints (17.2\%), withdrawal symptoms (15.5\%), and thought disorders (20\%).

Strong relation between dyslexia and internalizing manifestation specially anxiety among poor readers than control group was found also, in the study done by Goldston et al. (2007) [25].

Gender also show some difference in rating internalizing factors among children with dyslexia as in Willcutt and Pennington, (2000) [22]. They found marked gender difference in Withdrawn and Anxious- Depressed narrow-band scales similar to the broadband findings, which made the authors suggest that dyslexia is associated more strongly with elevations in these areas in females than males.

Bryan et al. (2004) suggested a vicious circle explaining the pathology of internalizing symptoms and disorders. Starting from the sense of scarce school self-efficacy, demotivation for homework, frequent mechanisms of learned helplessness, and difficulties in social integration, dyslexic children not only experience more suffering, but risk involving in vicious circles where failure, demoralization, poor metacognitive awareness, and lack of interest for school duties grow hand in hand. Other vicious circles may add to, if not precede, the above-mentioned ones, due to probable linguistic, attention, and self-regulatory difficulties connected with deficits of social skills, that seem to appear frequently in dyslexia [30].

\section{The relation between dyslexia and externalizing symptoms}

The association between psychopathological symptomatic behaviors in dyslexic subjects was recorded to be

Table 7 Mean scores of boys and girls on measures of Problem Scales of CBCL

\begin{tabular}{|c|c|c|c|c|c|c|c|}
\hline \multirow[t]{4}{*}{$\mathrm{CBCL}$ variables } & \multicolumn{2}{|l|}{ Boys } & \multicolumn{2}{|l|}{ Girls } & \multicolumn{2}{|c|}{ Main effects } & \multirow{3}{*}{$\begin{array}{l}\text { Group x } \\
\text { Gender } \\
\text { interaction }\end{array}$} \\
\hline & & & & & Group & Gender & \\
\hline & $(N=27)$ & $(N=26)$ & $(\mathrm{N}=23)$ & $(N=24)$ & & & \\
\hline & Mean \pm SD & Mean \pm SD & Mean \pm SD & Mean \pm SD & $\mathrm{F}$ & $\mathrm{F}$ & $\mathrm{F}$ \\
\hline Withdrawn & $54.2 \pm 7.5$ & $52.4 \pm 3.8$ & $57.1 \pm 8.9$ & $55.2 \pm 5.1$ & 1.94 & $4.4^{*}$ & 0.00 \\
\hline Somatic & $51.5 \pm 3.3$ & $51 \pm 2.4$ & $52.4 \pm 4.5$ & $51.8 \pm 2.8$ & 0.67 & 1.8 & 0.01 \\
\hline Anxious & $52.7 \pm 6.1$ & $50.5 \pm 1.6$ & $57 \pm 7.9$ & $51.7 \pm 2.9$ & $12.8^{* *}$ & $7.1^{* *}$ & 2.4 \\
\hline Social Problems & $51.6 \pm 4.1$ & $50.6 \pm 2.1$ & $52 \pm 4.2$ & $51.3 \pm 3.7$ & 1.3 & 0.52 & 0.01 \\
\hline Thought Problem & $50.6 \pm 2.01$ & $51.2 \pm 3.5$ & $51.3 \pm 3.5$ & $51 \pm 2.7$ & 0.08 & 0.21 & 0.52 \\
\hline Attention & $55.1 \pm 9.8$ & $50.8 \pm 2.9$ & $55.2 \pm 8.7$ & $51.3 \pm 3.2$ & $8.5^{* *}$ & 0.04 & 0.02 \\
\hline Delinquent & $57.6 \pm 9.7$ & $51.4 \pm 3.2$ & $52.6 \pm 5.8$ & $52.9 \pm 6.5$ & $4.6^{*}$ & 1.54 & $5.75^{*}$ \\
\hline Aggressive & $54.7+6.7$ & $50.8+2.1$ & $52.5+5.3$ & $51.3+2.8$ & $7.6^{* *}$ & 0.91 & 2.05 \\
\hline Internalizing & $45.9+11.2$ & $44.3+7.6$ & $53.2+11.9$ & $47.7+8.7$ & 3.2 & $7.2^{* *}$ & 0.97 \\
\hline Externalizing & $50.8+12.2$ & $42.7+7.2$ & $44.8+11.5$ & $41.6+10.5$ & $7.3^{* *}$ & 2.91 & 1.39 \\
\hline Total Score & $49.6+9.8$ & $42.3+6.4$ & $49.4+10.4$ & $42.7+10.4$ & $13.8^{* *}$ & 0.01 & 0.03 \\
\hline
\end{tabular}


61.0\% (Capozzi et al. (2007) [9]. Also, they found that $26.4 \%$ recorded a pathological score on the externalizing scale: attention/hyperactivity subscale was in which the children's scores most frequently fell within the clinical range. In fact, $46.5 \%$ of the sample obtained a score within the pathological range on the attention/hyperactivity scale. Only a minority of the sample obtained pathological scores on the two scales measuring aggressive and delinquent behavior (18\% and 15\%, respectively).

Gender also shows some difference in rating externalizing factors among children with dyslexia as in Willcutt and Pennington, (2000) study [22]. Individuals with dyslexia exhibited higher scores than individuals from the family control group on all externalizing measures.

Although both boys and girls with dyslexia exhibited higher levels of externalizing behaviors than individuals without dyslexia, significant interactions revealed a stronger association between dyslexic aggressive behaviors among males. One hypothesis is that boys with dyslexia may be more likely to act out in a disruptive manner and will therefore be identified more frequently by parents and teachers as in need of clinical attention. In contrast, an alternative hypothesis would propose that parents and teachers tend to value male academic achievement more than female academic achievement, and consequently expend greater effort to correct reading problems in male children. The results reported here are consistent with the first hypothesis, in that boys with dyslexia tended to exhibit elevations of externalizing behaviors, whereas girls with dyslexia exhibited higher levels of internalizing symptomatology that might be less apparent to parents or teachers.

In conclusion, the present study added an evidence for the high comorbidity of ADHD, ODD, and CD with dyslexia. Also, dyslexic boys show higher rates of externalized syndromes and girls show higher rates of internalized syndromes.

\section{Recommendations}

Assessment of children and adolescents with speech disorders for psychiatric disorders especially ADHD and opposition defiant disorder, have to be constant part of assessment of those patients. Also attention should be directed to internalized syndromes for girls and externalized syndromes for boys. This evaluation enables the psychiatrists to manage these children appropriately.

\section{Conclusion}

High comorbidity of other psychiatric disorders with dyslexia gets attention to evaluate students with dyslexia for other psychiatric comorbidity and referring them for psychiatric management.

\section{Abbreviations}

DSM IV-TR: Diagnostic and Statistical Manual of Mental Disorders-Text Revised; CBCL: Child Behavioral Checklist; MINI-Kid: The Mini International Neuropsychiatric Interview-Kid; IQ: Intelligence quotient; CD: Conduct disorder; ADHD: Attention deficit hyperactivity disorder; OCD: Obsessive compulsive disorder

\section{Authors' contributions}

$A D$ contributed in the study design, interpretation of the data, and preparing and revising the manuscript. YS contributed in the study design, collected and analyzed, interpreted the data, and prepared the main manuscript. HK contributed in the study design, interpretation of the data, and writing the manuscript. RH contributed in analyzing, interpretation of the data, and revising the manuscript. MA contributed in analyzing, interpretation of the data, and revising the manuscript. All authors approved the final manuscript.

\section{Funding}

The current study was not supported by any national or international institution or organization.

\section{Availability of data and materials}

The data sets generated and/or analyzed during the current study are available from the corresponding author on reasonable request.

\section{Competing interest}

The authors declare that they have no competing interests

\section{Ethics approval and consent to participate}

Before starting data collection, approvals to conduct the study were obtained from the Ethical Review Committee of Assiut Faculty of Medicine and the administrative authority in Neurological and Psychiatric Hospital at Assiut University. Prior to the interview, written informed consent was obtained from the literate participants and was signed in the presence of a witness for illiterate ones. Privacy and secrecy of all data were assured by ensuring the anonymity of the questionnaire, interviewing the participants separately in a closed room, and keeping data files in a safe place.

\section{Consent for publication}

Not applicable

Received: 14 April 2020 Accepted: 22 April 2020

Published online: 14 July 2020

\section{References}

1. Daniel L. Schacter, Daniel T. Gilbert, Daniel M. Wegner (2011) [2009]. Psychology, 2nd edition. Worth Publishers. p. 264. ISBN 978-1-4292-3719-2.

2. Mash EJ, Hunsley J (2010) Evidence-based assessment of child and adolescent disorders: issues and challenges

3. Phillips S, Kelly K, Symez L (2013). Assessment of learners with dyslexic-type difficulties. SAGE. P.7. ISBN 978-1-4462-8704-0.

4. Edelbrock C, Costello A (2011) Convergence between statistically derived behavior problem syndromes and child psychiatric diagnoses. J Abnorm Child Psychol 16:219-231

5. Chapman, J, Tunmer, W. (2000). Research on the reading edge: three common beliefs about literacy acquisition, including a lesson from reading recovery. Keynote address to the New Zealand Speech Language Therapists annual conference, Napier, 5 April.

6. Farrag AF, El-Behery AA (1985) Assiut dyslexia screening test. Assiut Med J 8:62-69

7. Hanaa Abdel hakim (2003): Learning disability prevalence and impact in primary school children .by Hanaa Abdel hakim et al. the Egyptian journal of community medicine vol. 21 p31:52

8. Catts HW, Adlof SM, Hogan T, Weismer SE (2005) Are specific language impairment and dyslexia distinct disorders? Journal of Speech, Language and Hearing Research 48:1378-1396

9. Willcutt EG, Pennington BF, Boada R, Ogline JS, Tunich RA, Cohhabildas NA, Olsen RK (2001) A comparison of the cognitive deficits in reading disability and attention-deficit/hyperactivity disorder. J Abnorm Psychol 110:157-172

10. W. Farghally, M.A. Abdel Hamid, A. Mamdouh (2015). Screening of primary school children for learning disabilities in Assiut City.MD thesis (None published). 
11. Laurent J, Swerdlik M, Ryburn M (1992) Review of validity research on the Stanford-Binet intelligence scale: Fourth edition. Psychol Assess 4:102-112

12. Abd-El-Tawab A (2004) The socioeconomic level of family index- revised. ElNahda library, Cairo, Egypt

13. Achenbach TM, Edelbrock C (1991) Manual for the Child Behavior Checklist and Profile. University of Vermont Department of Psychiatry, Burlington, VT

14. Achenbach TM, Rescorla LA (2000) Manual for the ASEBA Preschool Forms \& Profiles. University of Vermont, Research Center for Children, Youth, \& Families, Burlington, VT

15. Sheehan DV, Lecrubier $Y$, Harnett-Sheehan $K$, Amorim $P$, Janavs J, Weiller $E$, Hergueta T, Baker R, Dunbar G (1998) The Mini International Neuropsychiatric Interview (M.I.N.I.): The Development and Validation of a Structured Diagnostic Psychiatric Interview. J Clin Psychiatry 59(Suppl. 20):22-33

16. Kaplan B, Dewey DM, Crawford SG, Wilson BN (2001) The term co-morbidity is of questionable value in reference to developmental disorders: data and theory. J Learn Disabil 34(6):555-565

17. Larson K, Russ A Shirley, Kahn, RS, MPH, Halfen N (2007). Pattern of comorbidity functioning and services uses for U.S. children with ADHD. Pediatrics 2011 101:10.15421 Peds. 2010-0165.

18. Willcutt EG, Pennington BF (2000) Comorbidity of reading disability and attention-deficit hyperactivity disorder: Differences by gender and subtype. J Learn Disabil 33:179-191

19. Hsiung G. Y., Kaplan B. J., Petryshen T. L., Lu S., Field L. L. (2004). A dyslexia susceptibility locus (DYX7) linked to dopamine D4 receptor (DRD4) region on chromosome 11p15.5. Am. J. Med. Genet. 125B, 112-11910.1002/ajmg.b.20082

20. Saudino KJ, Plomin R (2007) Why are hyperactivity and academic achievement related? Child Dev 78:972-986

21. DuPaul GJ, Volpe RJ (2009) ADHD and learning disabilities: Research findings and clinical implications. Current Attention Disorders Reports 1:152-155

22. Willcutt EG, Pennington BF (2000) Psychiatric comorbidity in children and adolescents with reading disability. J Child Psychol Psychiatry Allied Discip 41(8):1039-1048

23. Svetaz MV, Ireland M, Blum R (2000) Adolescents with learning disabilities: risk and protective factors associated with emotional well-being: findings from a National Longitudinal Study of Adolescent Health. J Adolesc Health 27:340-348

24. Beitchman JH, Young AR (1997) Learning disorders with a special emphasis on reading disorders: a review of the past 10 years. J Am Acad Child Adolesc Psychiatry 36:1020-1032

25. Goldston DB, Walsh A, Arnold EM, Reboussin BA, Daniel SS, Erkanlil A, Nutter D, Hickman E, Palmes G, Snider E, Wood FB (2007) Reading problems, psychiatric disorders, and functional impairment from mid- to late adolescence. J Am Acad Child Adolesc Psychiatry 46(1):25-32

26. Hinshaw SP (1992) Academic underachievement, attention deficits, and aggression: comorbidity and implications for intervention. J Consult Clin Psychol 60(6):893-903. https://doi.org/10.1037/0022-006X.60.6.893

27. Heiervang E, Stevenson J, Lund A, Hugdahl K (2001) Behavior problems in children with dyslexia. Nord J Psychiatry 55:251-256

28. Eissa M (2010) Dyslexia, behavior problems, emotional problems, adolescence. Curr Psychiatr Ther 17(1):39-47

29. Capozzi F, Casini MP, Romani M (2008) Psychiatric co-morbidity in learning disorder: analysis of family variables. Child Psychiatry Hum Dev 39:101-110. https://doi.org/10.1007/s10578-007-0074-5

30. Bryan T, Burstein K, Cevriye E (2004) The social-emotional side of learning disabilities: a science-based presentation of the state of art. Learn Disabil Q 27:45-51

\section{Publisher's Note}

Springer Nature remains neutral with regard to jurisdictional claims in published maps and institutional affiliations.

\section{Submit your manuscript to a SpringerOpen ${ }^{\circ}$ journal and benefit from:}

- Convenient online submission

- Rigorous peer review

- Open access: articles freely available online

- High visibility within the field

- Retaining the copyright to your article

Submit your next manuscript at $\boldsymbol{\nabla}$ springeropen.com 